\title{
Progesterone and insulin stimulation of CPEB-dependent polyadenylation is regulated by Aurora A and glycogen synthase kinase-3
}

\author{
Madathia Sarkissian, Raul Mendez, ${ }^{1}$ and Joel D. Richter ${ }^{2}$ \\ Program in Molecular Medicine, University of Massachusetts Medical School, Worcester, Massachusetts 01605, USA
}

\begin{abstract}
Progesterone stimulation of Xenopus oocyte maturation requires the cytoplasmic polyadenylation-induced translation of mos and cyclin B mRNAs. One cis element that drives polyadenylation is the CPE, which is bound by the protein CPEB. Polyadenylation is stimulated by Aurora A (Eg2)-catalyzed CPEB serine 174 phosphorylation, which occurs soon after oocytes are exposed to progesterone. Here, we show that insulin also stimulates Aurora A-catalyzed CPEB S174 phosphorylation, cytoplasmic polyadenylation, translation, and oocyte maturation. However, these insulin-induced events are uniquely controlled by PI 3 kinase and PKC- $\zeta$, which act upstream of Aurora A. The intersection of the progesterone and insulin signaling pathways occurs at glycogen synthase kinase 3 (GSK-3), which regulates the activity of Aurora A. GSK-3 and Aurora A interact in vivo, and overexpressed GSK-3 inhibits Aurora A-catalyzed CPEB phosphorylation. In vitro, GSK-3 phosphorylates Aurora A on S290/291, the result of which is an autophosphorylation of serine 349. GSK-3 phosphorylated Aurora A, or Aurora A proteins with S290/291D or S349D mutations, have reduced or no capacity to phosphorylate CPEB. Conversely, Aurora A proteins with S290/291A or S349A mutations are constitutively active. These results suggest that the progesterone and insulin stimulate maturation by inhibiting GSK-3, which allows Aurora A activation and CPEB-mediated translation.
\end{abstract}

[Keywords: Insulin; GSK-3; Xenopus oocytes; Aurora A; cytoplasmic polyadenylation; CPEB]

Received July 23, 2003; revised version accepted November 19, 2003.

Fully grown Xenopus oocytes arrested at the end of prophase I are stimulated to re-enter into the meiotic divisions (oocyte maturation) by progesterone. Although the initial signaling event that is propagated by progesterone is unclear, it involves an immediate but transient decrease in cyclic AMP (cAMP; Sadler and Maller 1989; for review, see Ferrell 1999) and the activation of Aurora A (Eg2), a member of the Aurora family of protein kinases (Andresson and Ruderman 1998). The most proximal known substrate of Aurora A is CPEB, a sequence-specific RNA binding protein that stimulates cytoplasmic polyadenylation and translational activation (Hake and Richter 1994; Mendez et al. 2000a). CPEB interacts with the cytoplasmic polyadenylation element (CPE), a cis element present in the $3^{\prime}$ untranslated regions (UTRs) of several mRNAs including those that encode mos and cyclin B. The translation of mos mRNA is necessary to induce the MAP kinase cascade that indirectly activates $\mathrm{M}$-phase promoting factor (MPF), a heterodimer of cyclin

${ }^{1}$ Present address: Center for Genomic Regulation, Passeig Maritim 37-49, 08003 Barcelona, Spain.

${ }^{2}$ Corresponding author.

E-MAIL Joel.Richter@umassmed.edu; FAX (508) 856-4289.

Article and publication are at http://www.genesdev.org/cgi/doi/10.1101/ gad.1136004.
$\mathrm{B}$ and cdc2. MPF is responsible for many manifestations of oocyte maturation such as germinal vesicle breakdown (GVBD). Aurora phosphorylation of CPEB serine 174 enhances the association of CPEB with CPSF (cleavage and polyadenylation specificity factor), possibly helping to stabilize this group of proteins on the AAUAAA hexanucleotide, a second cis element essential for polyadenylation (Mendez et al. 2000a,b). CPSF is probably responsible for recruiting poly(A) polymerase to the end of the mRNA.

Polyadenylation-induced mRNA translation requires maskin, a CPEB and eIF4E-associated factor (StebbinsBoaz et al. 1999). Translation of CPE-containing RNAs is repressed in oocytes because the maskin-eIF4E interaction precludes an eIF4G-eIF4E interaction, which is necessary to correctly position the 40 s ribosomal subunit on the $5^{\prime}$ end of the mRNA. During maturation, the newly elongated poly(A) tail is bound by poly(A) binding protein (PABP); PABP subsequently interacts with eIF4G, and together they displace maskin from eIF4E, thereby stimulating translation (Cao and Richter 2002).

Cytoplasmic polyadenylation is not unique to maturing Xenopus oocytes; it occurs in the oocytes and/or embryos of Drosophila, mice, clams, and sea urchins, and thus is probably a general feature of early metazoan de- 
velopment (for review, see Richter 2000; Mendez and Richter 2001). Cytoplasmic polyadenylation also takes place in vertebrate and invertebrate neurons following synaptic activation (Wu et al. 1998; Wells et al. 2001; Huang et al. 2002; Liu and Schwartz 2003). In mammalian neurons, CPEB undergoes Aurora A-mediated phosphorylation in response to N-methyl-D-aspartate receptor signaling (Huang et al. 2002), thus demonstrating that progesterone is not the only agent that can induce Aurora-mediated activity; indeed, in this regard progesterone signaling may be unique to Xenopus oocytes.

To begin to analyze a widely used signaling cascade that might impact Aurora activity more generally, we have focused on the insulin signaling pathway. Under certain circumstances insulin can stimulate Xenopus oocyte maturation, which in contrast to progesterone, requires phosphoinositide 3-kinase (PI3 kinase) and protein kinase C (isoform zeta) activity (Sadler and Maller 1989; Dominguez et al. 1992; Berra et al. 1993; Liu et al. 1995). At least in mammalian cells, insulin can also signal through glycogen synthase kinase 3 (GSK-3), whose activity is usually downregulated in response (Frame and Cohen 2001; Oriente et al. 2001). In oocytes, the downregulation of GSK-3 activity is also thought to be necessary for progesterone stimulation of oocyte maturation (Fisher et al. 1999). The possible involvement of GSK-3 in insulin-stimulated maturation is not known, nor is (are) the substrate(s) upon which it might act following either progesterone or insulin treatment.

In this study, we show that insulin stimulation of oocyte maturation requires Aurora A-catalyzed CPEB serine 174 phosphorylation and CPE-dependent cytoplasmic polyadenylation. Although insulin-induced, but not progesterone-induced, Aurora A activation is mediated by PI3 kinase and $\mathrm{PKC}-\zeta$, both pathways require the inactivation of GSK-3 for oocyte maturation. In immature oocytes, GSK-3 binds to Aurora A, and the overexpression of GSK-3 in injected oocytes inhibits CPEB-mediated translation and maturation. In vitro, GSK-3 phosphorylates Aurora A on S290/291, the result of which is an Aurora A autophosphorylation at S349. Autophosphorylated Aurora A has a reduced capacity to phosphorylate a CPEB substrate. Furthermore, an Aurora A containing S290/291D or S349D mutations has no capacity to phosphorylate the same CPEB substrate. Conversely, Aurora A proteins with S290/291A or S349A mutations are constitutively active. These results demonstrate that the progesterone and insulin signaling pathways stimulate CPEB-mediated translation and oocyte maturation by alleviating the GSK-3 inhibition of Aurora A activity.

\section{Results}

Insulin induces CPE-dependent mRNA polyadenylation and translation

To determine whether CPE-dependent mRNA polyadenylation is a response to insulin signaling, stage VI Xenopus oocytes were injected with radiolabeled CPE-containing and CPE-lacking RNA. Some of the oocytes were then incubated in the presence of progesterone or insulin until a white spot at the animal pole was observed, an indication of germinal vesicle breakdown (GVBD) and oocyte maturation. RNA from the oocytes was then extracted and analyzed by gel electrophoresis and autoradiography. Both insulin- and progesterone-induced polyadenylation in a CPE-dependent manner (Fig. 1A).

To assess whether polyadenylation was accompanied by CPEB phosphorylation, an event necessary for the activity of this protein, an in vitro kinase assay was performed using extracts from mock-, progesterone-, or insulin-treated oocytes supplemented with recombinant CPEB and $\left[\gamma^{32} \mathrm{P}\right]$ ATP, which was followed by SDS-PAGE. As expected, both progesterone- and insulin-treated oocytes contained newly synthesized mos as well as high MPF (H1 kinase) activity, demonstrating that they had undergone maturation; they also displayed CPEB phosphorylating activity. To examine whether insulin, like progesterone (Mendez et al. 2000a, 2002) leads to the polyadenylation requiring CPEB serine 174 phosphorylation, two-dimensional (2D) phospho-peptide mapping was performed. Two prevalent phospho-peptides were observed, one of which (Fig. 1B, arrow) was not detected when a CPEB with an S174A mutation was used as the substrate. Thus, insulin stimulation leads to CPEB serine 174 phosphorylation as well as mos synthesis and MPF activation.

\section{Insulin signaling requires Aurora A-catalyzed CPEB serine 174 phosphorylation}

One characteristic of progesterone-induced maturation is the feedback of downstream kinases to activate (or potentiate) upstream events. For example, MPF (cyclinB/ cdc2), while clearly far downstream of initial CPEB activity (e.g., Mendez et al. 2002), can induce CPE-dependent polyadenylation if injected into oocytes or added to an extract prepared from immature oocytes (Paris et al. 1991). Because the elimination of such feedback loop(s) would allow us to focus on upstream insulin-signaling events, we ablated mos mRNA with an antisense oligonucleotide, which should prevent MAP kinase and MPF activation (Sagata et al. 1988). Figure 2A shows that indeed the mos antisense oligonucleotide not only prevented insulin- (and progesterone-) stimulated mos synthesis, which is essential for the MAP kinase cascade, it also prevented MPF activity. However, the mos antisense oligonucleotide (directed against the coding region) had no effect on the insulin- or progesterone-stimulated polyadenylation of injected mos 3' UTR (Fig. 2A). Thus, the insulin and progesterone pathways must converge at a point upstream of mos mRNA polyadenylation.

Phosphorylation of CPEB serine 174 is essential for progesterone-induced cytoplasmic polyadenylation during oocyte maturation (Mendez et al. 2000a). To determine whether this event is important for insulin-induced maturation, oocytes were injected with mRNA encoding either epitope-tagged wild-type $\mathrm{CPEB}$, or a CPEB containing a serine 174 and serine 180 to alanine (S174A, S180A) mutation. (S174 lies within the first of 
Sarkissian et al.

A
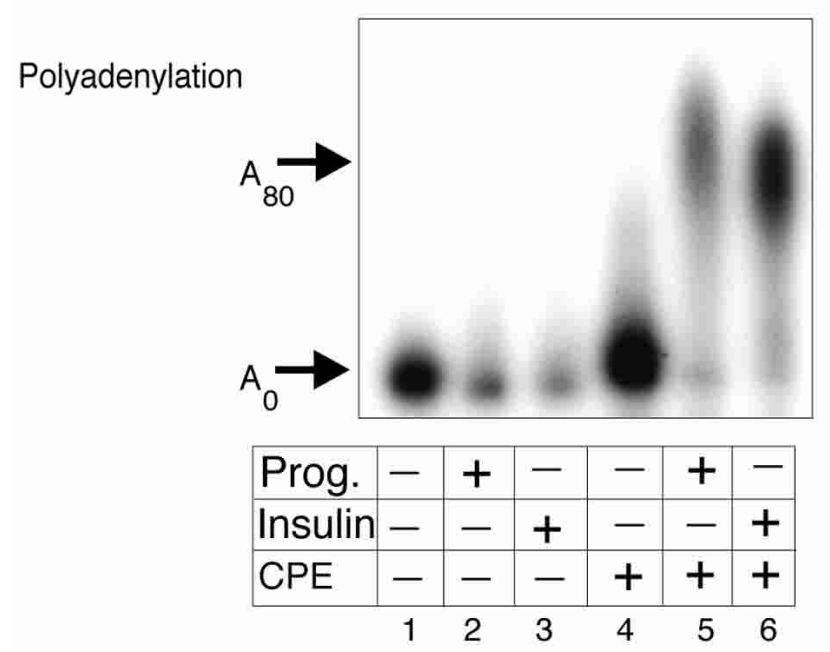

B

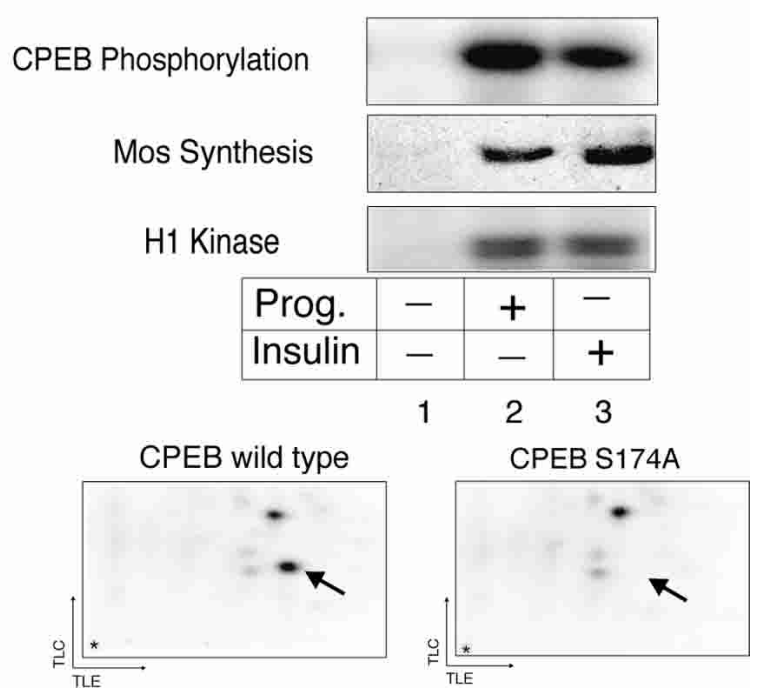

Figure 1. Insulin stimulation of CPE-dependent polyadenylation. $(A)$ In vitro synthesized radiolabeled RNA, containing or lacking a CPE, was injected into stage VI oocytes, some of which were incubated in the presence of progesterone or insulin. When a white spot was visible at the animal pole of these stimulated oocytes, the RNA was extracted and analyzed for polyadenylation by denaturing polyacrylamide gel electrophoresis. (B) Extracts prepared from unstimulated and stimulated (progesterone or insulin) oocytes were supplemented with purified recombinant histidine-tagged CPEB and $\gamma^{32} \mathrm{P}$-ATP in an in vitro kinase assay. Following the kinase reaction, phospho-CPEB was analyzed by SDS-PAGE and autoradiography. Mos was detected by a Western blot, and MPF activity by an $\mathrm{H} 1$ kinase reaction. Extracts from insulin-stimulated oocytes were supplemented with recombinant wild-type CPEB, or recombinant CPEB with S174A and S180A mutations (see text for details), together with $\gamma^{32}$ P-ATP. The resulting phosphorylated CPEB proteins were subjected to $2 \mathrm{D}$ phospho-peptide mapping. The arrow indicates the location of the peptide containing phospho-serine 174 .

two LDSR motifs in CPEB; S180 lies within the second. Although we have no evidence that S180 is ever phosphorylated, both serine residues were changed to alanine to eliminate a possible compensatory phosphorylation of S180 if S174 was eliminated; cf. Mendez et al. 2000a.) The oocytes were then incubated with insulin and scored for oocyte maturation. Figure $2 \mathrm{~B}$ shows that although myc-tagged wild-type and LDSR mutant CPEB proteins were synthesized to the same extent (inset, oocyte maturation), only the mutant CPEB protein inhibited both maturation and MPF activity. Not surprisingly, the LDSR mutant CPEB protein also inhibited insulininduced mos synthesis. These results indicate that insulin-stimulated maturation, like progesterone-stimulated maturation, requires CPEB serine 174 phosphorylation.

Eg2, the Xenopus homolog of Aurora A, is a serine/ threonine kinase (Andresson and Ruderman 1998; Littlepage et al. 2002) that phosphorylates CPEB serine 174 in progesterone-treated oocytes (Mendez et al. 2000a). To investigate the necessity of this kinase for insulin signaling, we employed a model peptide substrate derived from CPEB that obviates the need for 2D peptide mapping (Mendez et al. 2000a). For example, when this peptide is affixed to ovalbumin (a molar ratio of $\sim 8$ to 1 ), it serves as an efficient substrate for phosphorylation by either recombinant Aurora A or extracts prepared from progesterone-matured oocytes (Fig. 2C; Mendez et al. 2000a). However, a mutant peptide with an LDAR motif was not phosphorylated (Fig. 2C). Most significantly, immunodepletion of Aurora A from extracts derived from insulin-stimulated oocytes significantly depressed CPEB peptide phosphorylation (cf. mock depletion, Fig. 2C). These data indicate that Aurora A is an integral component of the insulin signaling pathway.

\section{PI3 kinase and PKC- $\zeta$ are essential intermediaries} between insulin stimulation and Aurora A activation

Although the results presented above indicate that insulin and progesterone employ many of the same signaling components to promote oocyte maturation, there are some important differences between the two (Dominguez et al. 1992; Berra et al. 1993). For example, although decreased cAMP levels are required for both progesterone- and insulin-mediated maturation (Sadler and Maller 1989), PI3 kinase is required only for the insulin pathway (Berra et al. 1993; Liu et al. 1995). Because it seemed likely that insulin-stimulated CPE-mediated and Aurora A-dependent mRNA polyadenylation and translation could also rely on PI3 kinase, oocytes were treated with wortmannin, a PI3 kinase inhibitor (Wymann et al. 1996), prior to insulin or progesterone stimulation. Although wortmannin had no effect on any progesterone-stimulated parameter that we measured, as expected, this agent blocked insulin-stimulated maturation and MPF activity (Fig. 3A). Most importantly, wortmannin also inhibited insulin-stimulated CPEB phosphorylation and cytoplasmic polyadenylation.

Two downstream targets activated by insulin-induced PI3 kinase signaling are FRAP/mTOR and PKC- $\zeta$ (for re- 
A
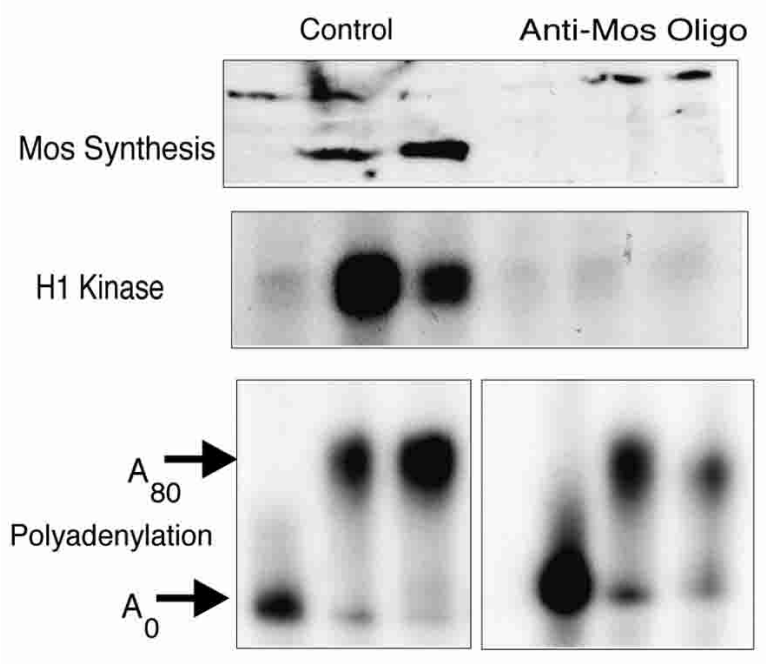

\begin{tabular}{|c|c|c|c|c|c|c|}
\hline Prog. & - & + & - & - & + & - \\
\hline Insulin & - & - & + & - & - & + \\
\hline
\end{tabular}

C

Peptide Phosphorylation
B
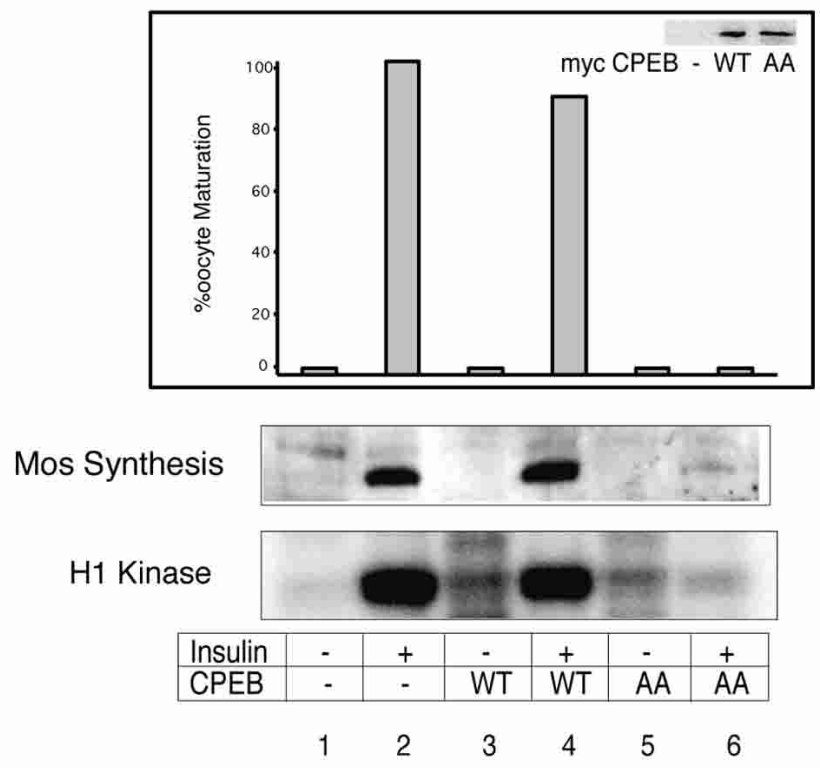

Immuno-depletion of Aurora
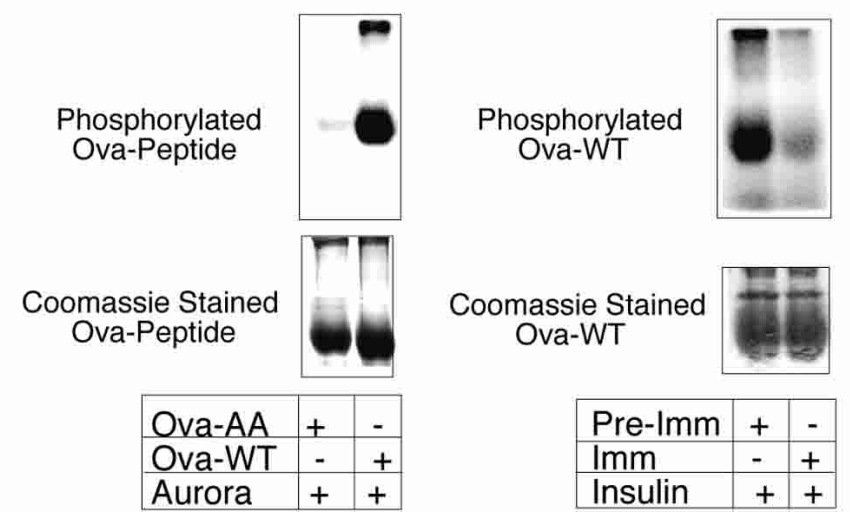

\begin{tabular}{|l|c|c|}
\hline Pre-Imm & + & - \\
\hline Imm & - & + \\
\hline Insulin & + & + \\
\hline
\end{tabular}

Figure 2. Aurora-stimulated CPEB phosphorylation is required for insulin-induced maturation. $(A)$ Oocytes were injected with a mos antisense oligonucleotide and then stimulated with progesterone or insulin. Some of the oocytes were also injected with CPEcontaining radiolabeled RNA. Mos, MPF, and polyadenylation were analyzed as described in Fig. 1. (B) Oocytes were injected with in vitro synthesized mRNAs encoding myc-tagged wild-type CPEB or a CPEB with S174A and S180A mutations, some of which were then stimulated with insulin. The oocytes were then scored for maturation (GVBD), and the expression levels of the injected CPEB mRNAs were determined by ${ }^{35} \mathrm{~S}$-methionine labeling and immunoprecipitation with myc antibody, followed by SDS-PAGE and autoradiography (inset). Mos protein and MPF activity were assayed as described in Fig. 1. (C) A peptide corresponding to CPEB residues 163-181, and another containing the same sequence but with S174A, S180A changes were coupled to ovalbumin, and are referred to as Ova-WT and Ova-AA, respectively. The coupled peptides were subjected to in vitro kinase assays with E.coli-expressed Aurora A and analyzed by SDS-PAGE and autoradiography. Coomassie blue staining of the gel shows equal loading of peptide conjugates (peptide phosphorylation). Extracts from insulin-stimulated oocytes were either mock-depleted with pre-immune serum or immunodepleted with Aurora A antibody; the depleted fractions were then subjected to in vitro kinase assays with Ova-WT peptide, which was analyzed by SDS-PAGE and autoradiography. Coomassie blue staining of the gel shows equal loading of the peptide conjugate (immunodepletion of Aurora).

view, see Mendez et al. 2001; Cantley 2002). FRAP/ mTOR can stimulate mRNA translation by activating S6 kinase (Schmelzle and Hall 2000; Kozma and Thomas 2002) and inactivating eIF4EBP (Gingras et al. 2001). To determine whether FRAP/mTOR functions in CPE-me- diated mRNA translation, oocytes were incubated in media containing rapamycin, a specific inhibitor of this kinase (Schwab et al. 1999) prior to hormone treatment. Although rapamycin-treated oocytes matured slightly faster when stimulated with progesterone compared to 
Sarkissian et al.

A
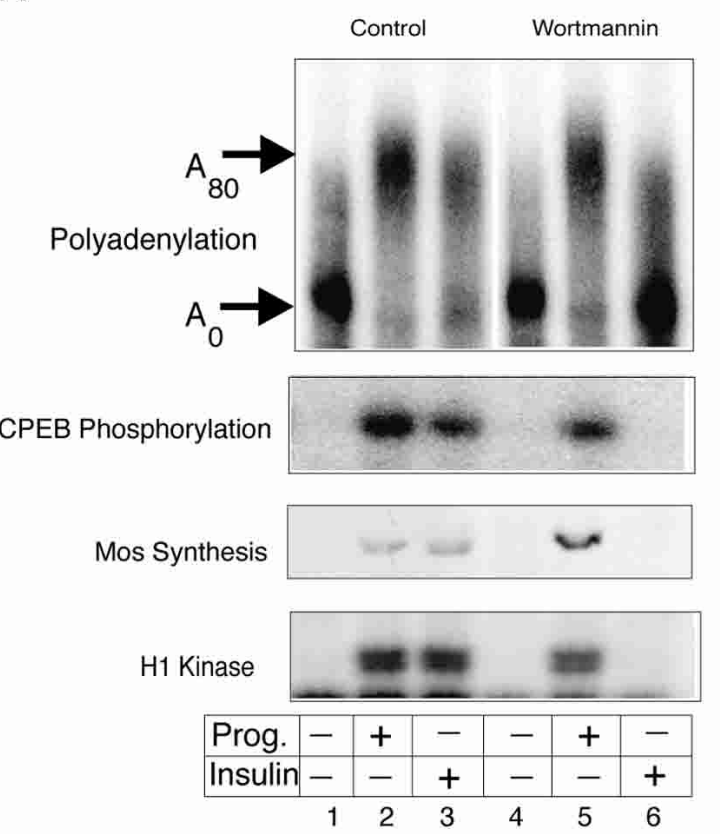

B
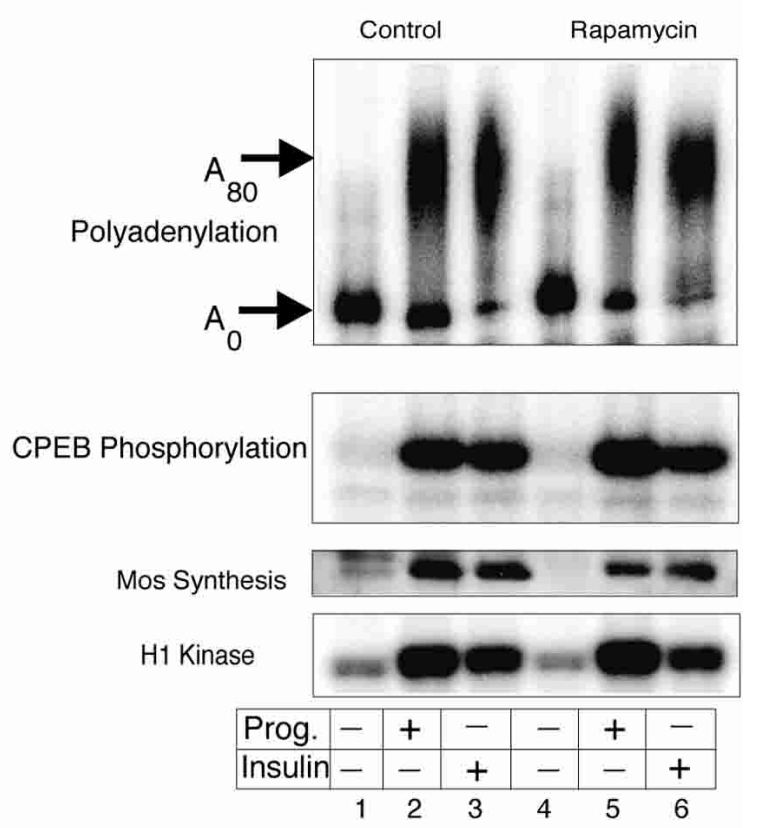

C

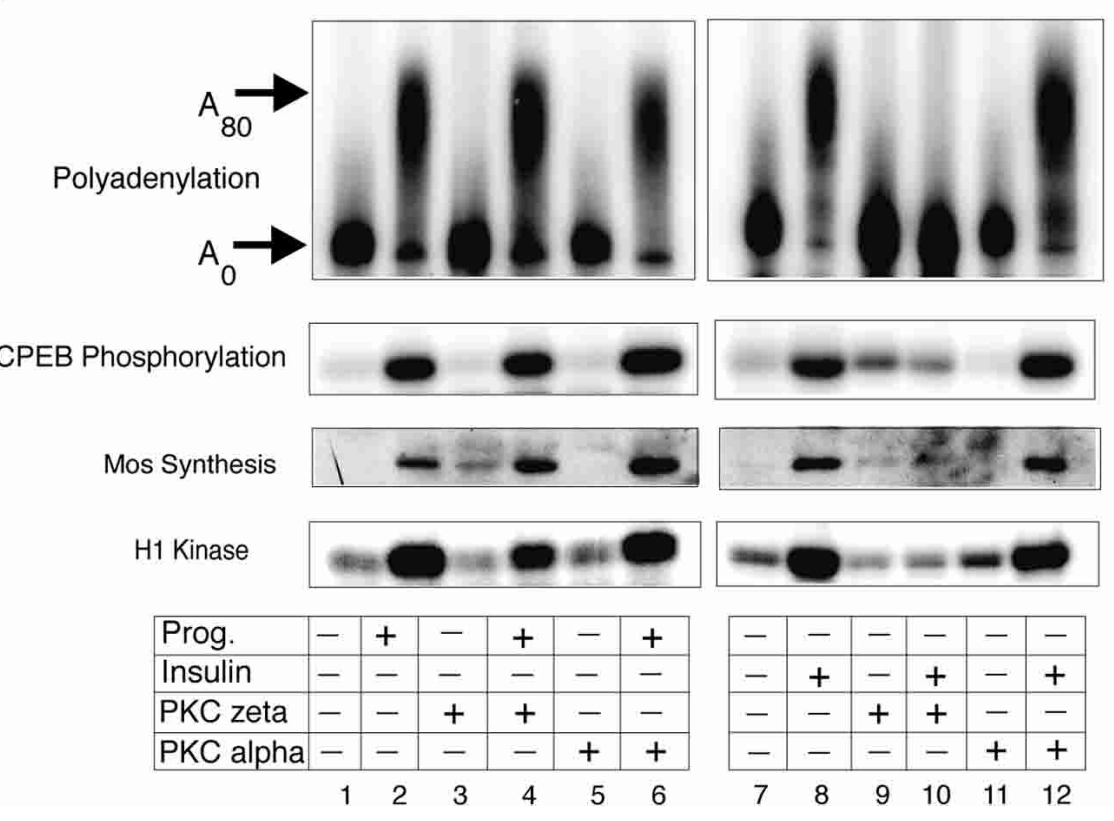

Figure 3. PI 3 kinase and PKC- $\zeta$ are required for insulin-stimulated polyadenylation. $(A)$ Oocytes were incubated with wortmannin for $2 \mathrm{~h}$ and then in some cases, injected with CPE-containing RNA, which was followed by stimulation with progesterone or insulin. MPF activity, mos protein levels, CPEB phosphorylation, and cytoplasmic polyadenylation were then assessed as described in Fig. 1. (B) Oocytes were incubated with rapamycin for $2 \mathrm{~h}$, injected with CPE-containing RNA, and the same parameters as in panel $A$ were assayed. $(C)$ Oocytes were injected with PKC- $\zeta$ inhibitor peptide, PKC- $\alpha$ inhibitor peptide, or mock-injected, and induced to mature with insulin or progesterone. The same parameters as in $A$ were assayed.

insulin (data not shown; Schwab et al. 1999), this reagent had no substantive effect on MPF activity, mos synthesis, CPEB phosphorylation, or cytoplasmic polyadenylation (Fig. 3B). These data indicate that insulin-stimulated PI3 kinase signaling does not affect CPEB activity through FRAP/mTOR.
To determine whether PKC- $\zeta$ is required for insulin-stimulated CPEB-induced polyadenylation, oocytes were injected with either a specific PKC- $\zeta$ inhibitor peptide or, as a control, a specific PKC- $\alpha$ inhibitor peptide (Dominguez et al. 1992), followed by progesterone or insulin treatment. Figure $3 \mathrm{C}$ demonstrates that whereas 
the PKC- $\alpha$ inhibitory peptide had no effect on either progesterone- or insulin-stimulated MPF activity, mos synthesis, CPEB phosphorylation, or cytoplasmic polyadenylation, the PKC- $\zeta$ inhibitor inhibited all of these events with insulin treatment. Therefore, insulin specifically signals through PI3 kinase and PKC- $\zeta$ to promote CPE-mediated mRNA polyadenylation.

\section{Glycogen synthase kinase 3 is an upstream negative regulator of Aurora $A$}

GSK-3 is a component of the insulin-signaling pathway that is inhibited by two upstream kinases, PKC- $\zeta$ and PKB/AKT (Frame and Cohen 2001; Oriente et al. 2001). In oocytes, GSK3 activity decreases during oocyte maturation, and its overexpression can inhibit progesteroneinduced maturation (Fisher et al. 1999). Indeed, whereas GSK-3 injection inhibited all progesterone- or insulinstimulated CPE-mediated signaling events including cytoplasmic polyadenylation, CPEB phosphorylation, mos synthesis, MPF activity, and oocyte maturation (Fig. 4A), the kinase-dead version of the enzyme had no effect (data not shown). These results suggest that not only is GSK-3 activity upstream of CPEB and Aurora A-mediated translation, but that the activity is inhibitory. If so, then perhaps GSK-3 inhibits Aurora A by directly phosphorylating the enzyme. To assess these possibilities, we performed both an in vivo binding experiment as well as in vitro kinase assays. Figure 4B (top) demonstrates that GSK-3 immunoprecipitation from oocytes also coprecipitates Aurora A, and that GSK-3 phosphorylates Aurora A (the kinase-dead version of Aurora A, K169R, was employed so that possible autophosphorylation would be eliminated) in vitro, primarily at one or two sites. By employing truncated Aurora A proteins for in vitro kinase reactions, we localized the site of GSK-3 phosphorylation of Aurora A as residing between residues 285 and 302 (Fig. 4B, bottom). Utilizing site-directed mutagenesis, the mutation of two serine residues, at positions S290 and S291, eliminated all phosphorylation of Aurora A by GSK-3 (Fig. 4B, bottom).

\section{Aurora $A$ is differentially phosphorylated during oocyte maturation}

The results presented thus far indicate that the progesterone and insulin signaling pathways control CPE-mediated mRNA translation through Aurora A function. Although the activation of this kinase requires a direct upstream Aurora A phosphorylating event (Andresson and Ruderman 1998; Walter et al. 2000; Eyers et al. 2003; Littlepage et al. 2002; Tsai et al. 2003; cf. Ma et al. 2003 for evidence of a biphasic activation of Aurora A during maturation), our data showing that GSK-3 phosphorylation of Aurora A is correlated with the inhibition of oocyte maturation (Fig. 4) suggest that Aurora A activity might also be subject to negative regulation. If true, sites of phosphorylation on Aurora A should decrease as oocyte maturation progresses. To investigate this possibility, extracts prepared from immature or progesterone- or insulin-stimulated oocytes were primed with recombi- nant Aurora A and $\gamma^{32}$ P-ATP; following an incubation period, Aurora A was isolated and processed for 2D phospho-peptide mapping. Figure 5A (top) shows that a phospho-peptide that was particularly prominent in immature oocyte extracts diminished upon progesterone-induced maturation; this decrease also occurred with insulin-induced maturation (insulin data not shown). A longer exposure of this same map (Fig. 5A, lower panel) shows that several additional phospho-peptides were similarly reduced during maturation (solid arrows); one also appeared to increase (open arrow). Although the structure of the most prevalent phospho-peptide in Figure 5A (top) is unknown, we noted that Littlepage et al. (2002) used mass spectrometry to identify S349 as one of several Aurora A-phosphorylated residues; these investigators also showed that an S349D mutation inhibited kinase activity of the enzyme. Because an Aurora A inhibitory phosphorylation might be expected to diminish during maturation, we suspected that the phospho-peptide shown in Figure 5A could contain S349. Indeed, an S349A mutation abolished the phosphorylation of this peptide (Fig. 5B).

\section{GSK-3 inhibits Aurora A activity through an autophosphorylation event}

If GSK-3 is an upstream negative regulator of Aurora A, then the kinase activity of Aurora A should be inhibited following GSK-3 phosphorylation. Figure 6A demonstrates that the ability of Aurora A to phosphorylate the CPEB-derived peptide (cf. Fig. 2) indeed was inhibited, by $\sim 50 \%$, when this kinase was phosphorylated by GSK-3.

Recent studies have indicated that Aurora A has autophosphorylation capabilities that lead to its activation. TPX2, a factor involved in mitotic spindle assembly, promotes this autophosphorylation on Aurora A T295 (Eyers et al. 2003; Tsai et al. 2003). We found that E. coliexpressed Aurora A, when pretreated with phosphatase prior to incubation with GSK-3, became phosphorylated on S349 (Fig. 6B). Because GSK-3 does not phosphorylate this site (see Fig. 4), this phosphorylation event must occur through an autophosphorylation mechanism.

These observations, coupled with our previous results showing that S349 phosphorylation diminishes as maturation progresses (Fig. 5A) and those of Littlepage et al. (2002) who demonstrated that phospho-S349 inhibits kinase activity, suggest that a priming phosphorylation on Aurora A S290/S291 by GSK-3 stimulates the Aurora A autophosphorylation at S349, which inhibits Aurora A catalytic activity. The importance of the negatively acting S349 autophosphorylation is underscored by the observation that an Aurora A mutant (S349A) retained almost all of its capacity to phosphorylate a CPEB substrate even when phosphorylated by GSK-3 (Fig. 6C). Furthermore, an Aurora A containing an S349D mutation was completely inactive (Fig. 6C), as demonstrated initially by Littlepage et al. (2002). Finally, the importance of the GSK-3 phosphorylation of Aurora A was shown by additional kinase reactions. An Aurora A containing S290A/S291A mutations retained its capacity to 
Sarkissian et al.

A
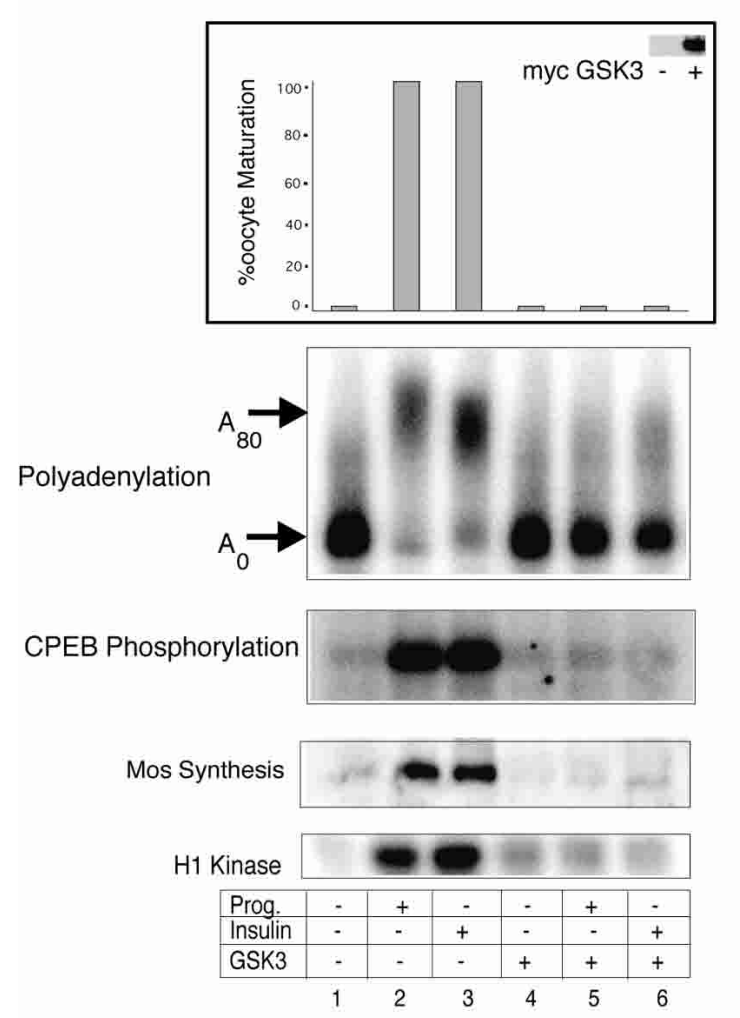

B

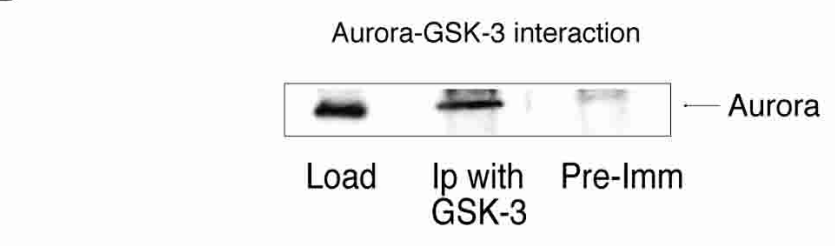

GSK-3 phosphorylation of Aurora

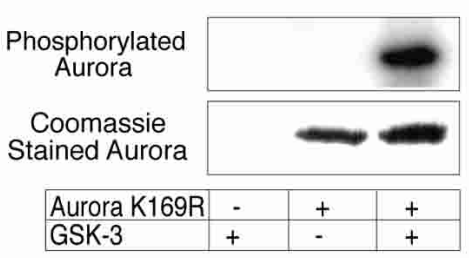

Phospho-aurora(K169R)
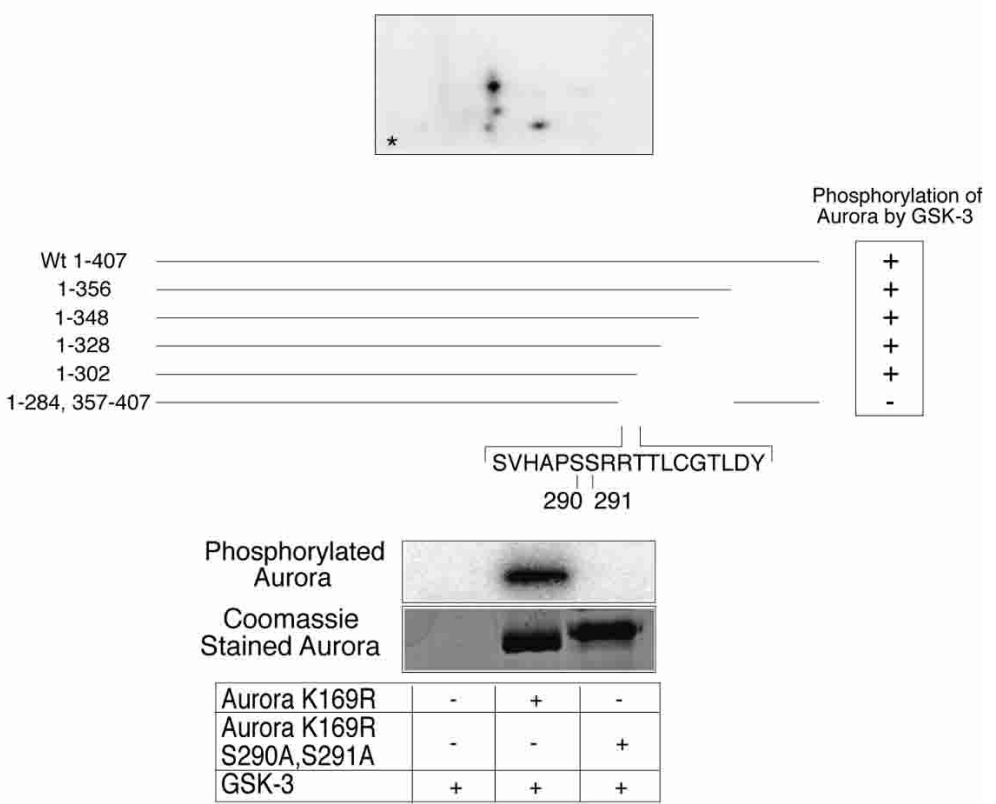

Figure 4. GSK-3 inhibits CPE-mediated translation in both insulin and progesterone signaling pathways. $(A)$ Oocytes were injected with mRNA encoding a myc-tagged wild-type GSK-3 (Pierce and Kimelman 1995), some of which were then stimulated with insulin or progesterone. The oocytes were then scored for maturation (GVBD). The expression level of the injected GSK-3 mRNA was determined by a Western blot using myc antibody (inset). Polyadenylation, CPEB phosphorylation, mos protein levels, and MPF activity were assayed as in Fig. 1. $(B)$ Oocyte extracts were immunoselected with GSK-3 antibody, or pre-immune serum, and then Western blotted and probed with Aurora A antibody (top). Purified kinase-dead Aurora A with a K169R mutation (to eliminate possible autophosphorylation) was incubated with recombinant GSK-3 and $\gamma^{32}$ P-ATP; phospho-Aurora was then analyzed by both SDS-PAGE and 2D phospho-peptide mapping. Several truncated Aurora A proteins, as well as a protein with S290/291A mutations, were expressed in E. coli, subjected to phosphorylation by recombinant GSK-3 in vitro, and analyzed by SDS-PAGE (bottom panel).

phosphorylate the CPEB-derived peptide substrate even in the presence of GSK-3. Conversely, Aurora A containing S290D/291D mutations was catalytically inactive (Fig. 6C). In addition, when Aurora A S290A/S291A was incubated in extracts derived from immature oocytes, the phosphorylation of S349 was substantially reduced compared to the wild-type protein (Fig. 6D). These data reaffirm that S290/291 phosphorylation is required for S349 phosphorylation in immature oocyte extracts.

To examine the in vivo requirement for these phos- phorylation events, we injected Aurora A wild-type as well as S290/291A and S349A mutant proteins into oocytes and examined the CPE-mediated polyadenylation of a reporter RNA. When stimulated with a low amount of progesterone $(0.01 \mu \mathrm{g} / \mathrm{mL})$, the Aurora A S290/291A and S349A mutant proteins enhanced the rate of RNA polyadenylation compared to both the control (noninjected) and the Aurora A wild-type protein (Fig. 6E, note 2-h timepoint). Aurora A S290/291A and S349A mutant proteins stimulated the rate of CPEB S174 phosphoryla- 
A

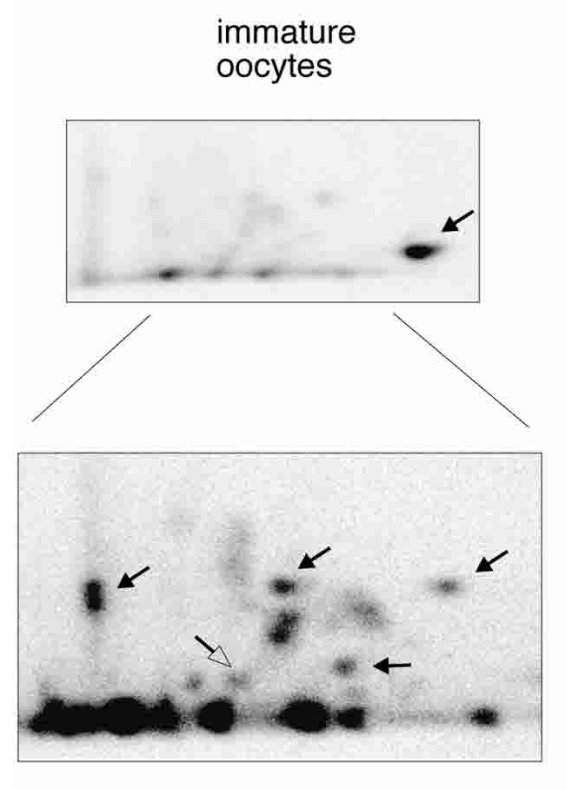

B

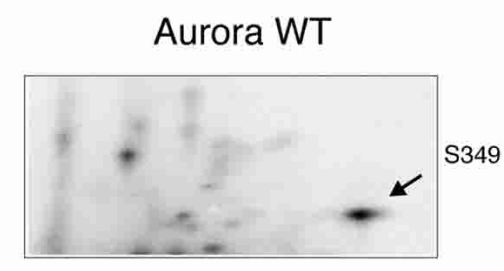

Progesterone mature oocytes
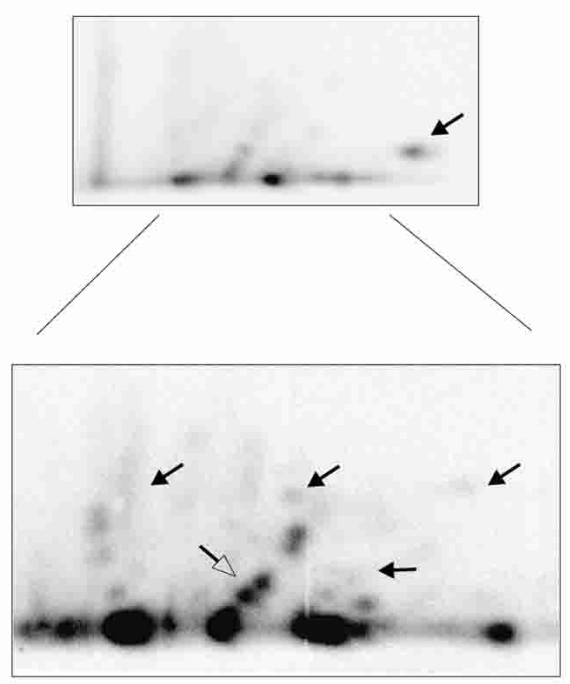

Aurora S349A

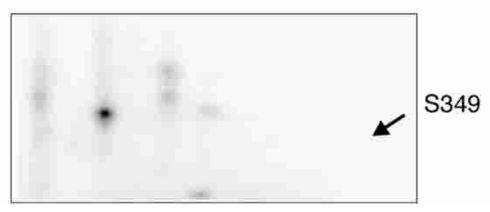

Figure 5. Aurora A is differentially phosphorylated during oocyte maturation. $(A)$ E. coli-expressed phosphatase-treated Aurora A was incubated in extracts from immature or progesterone-stimulated oocytes primed with $\gamma^{32} \mathrm{P}$-ATP. The resulting phosphorylated Aurora proteins were resolved by $2 \mathrm{D}$ phospho-peptide mapping. The top panel shows a short exposure; the bottom shows a longer exposure. Solid arrows indicate phospho-peptides that diminished during maturation; the open arrow denotes a phospho-peptide that increased during this time. $(B)$ Identical phospho-peptide mapping procedures were performed with wild-type or S349A Aurora A proteins. The arrow denotes the phospho-peptide that contains S349. tion as well (data not shown). Taken together, these results suggest that in immature oocytes, GSK-3 is an upstream kinase that phosphorylates and inactivates Aurora A through an autophosphorylation mechanism. Upon progesterone or insulin treatment, GSK-3 is inhibited, leading to the activation of Aurora A, the phosphorylation of CPEB, cytoplasmic polyadenylation, mRNA translation, and oocyte maturation.

\section{GSK-3-mediated Aurora A phosphorylation decreases during oocyte maturation}

The decrease in GSK-3 activity during progesterone-induced oocyte maturation (Fisher et al. 1999) is one important event that is required for Aurora A activation. We wished to determine whether GSK-3-mediated Aurora A phosphorylation activity also decreased during insulin-induced maturation. However, several experiments that would allow us to examine this possibility in a quantitative manner had to be performed first. We immunoprecipitated GSK-3 from extracts derived from immature oocytes and used this material as the kinase source to ensure that only GSK-3 activity would be monitored. GSK-3, which was successfully precipitated from immature oocyte extracts (Fig. 7A, top panel), phosphorylated a wild-type GSK-3 substrate peptide (derived from glycogen synthase) but not a mutant peptide (Fig. 7A, lower panel). One interesting fact about this sub- strate peptide is that it contains a phospho-serine residue (position 21) downstream of the GSK-3 phosphorylation site (position 17); S21 is necessary to "prime" the substrate for GSK-3 phosphorylation at serine 17 (Bijur et al. 2000).

To determine whether GSK-3 phosphorylation of Aurora $\mathrm{A}$ also requires a priming event, we incubated an Aurora A-derived peptide with protein kinase A (PKA); PKA is known to phosphorylate T295 (Eyers et al. 2003; Tsai et al. 2003), which is in a position similar to the priming site on the glycogen synthase peptide. When incubated with GSK-3 immunoprecipitated from immature oocyte extracts, the PKA-phosphorylated peptide was found to be a much better substrate than the peptide that lacked the PKA phosphorylation (Fig. 7B, left). This peptide, as well as one with an S290A/S291A mutation, was incubated with GSK-3 that was immunoprecipitated from control, progesterone-treated, or insulin-treated oocytes (Fig. 7B, right, note Western showing equal GSK-3 immunoprecipitation in all cases). Whereas the mutant peptide was a very poor phosphorylation substrate, the wild-type peptide was heavily phosphorylated by GSK-3 from immature oocytes. Moreover, the phosphorylation of the peptide decreased, albeit not dramatically, during both progesterone- and insulin-stimulated maturation.

To confirm that Aurora A is indeed T295-phosphorylated in vivo, oocyte extracts were subjected to Western blot analysis using a phospho-specific antibody directed 
Sarkissian et al.

A

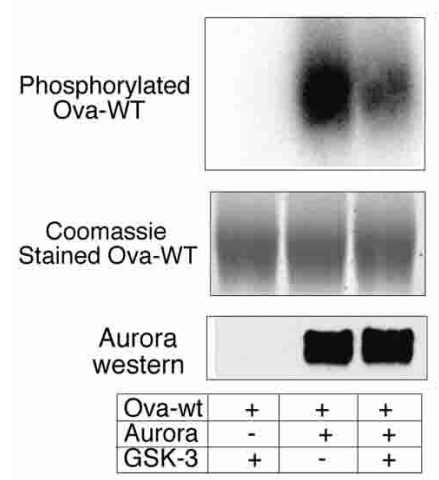

B
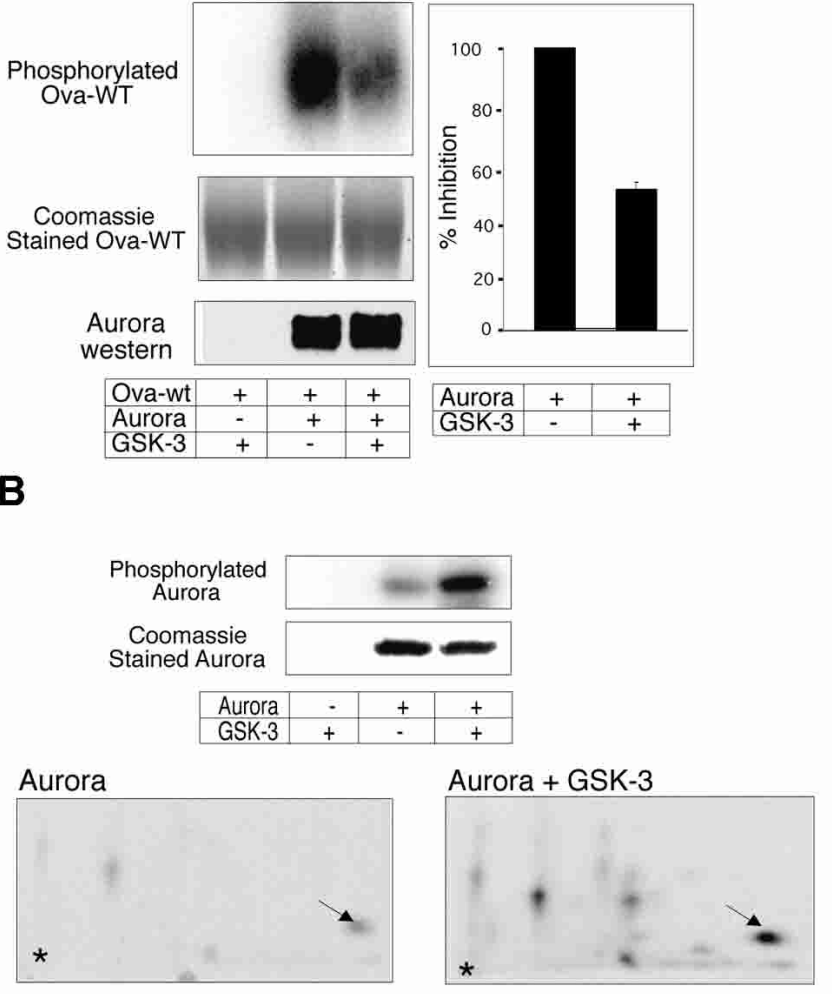

C

Aurora

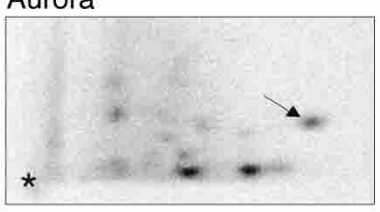

Aurora S290A,S291A

E

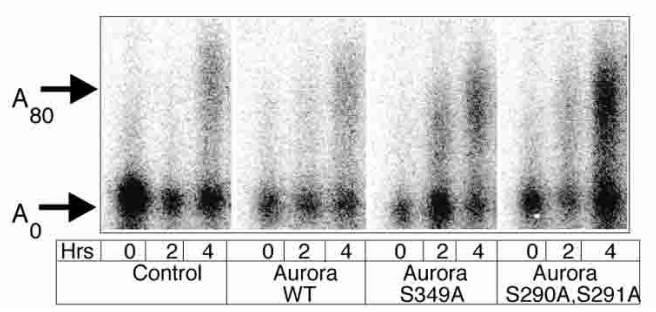

Figure 6. GSK-3 inhibits Aurora A kinase activity. (A) Aurora A was incubated with or without recombinant GSK-3, purified, then used to phosphorylate the CPEB-derived peptide substrate. Top panel: the radiolabeled CPEB peptide (Ova-WT peptide); middle panel: a Coomassie blue-stained gel showing equal loading of Ova-WT; lower panel: a Western blot of Aurora A showing equal amounts used in the assay. The histogram quantifies the amount of phosphorylated peptide from three experiments $(P<0.05$, Student's $t$-test $)$. $(B)$ Phosphatase-treated Aurora A incubated with GSK-3 and $\gamma^{32}$ P-ATP was analyzed by SDS-PAGE and 2D phospho-peptide mapping. The arrow refers to an Aurora A autophosphorylated phospho-peptide that was stimulated by recombinant GSK-3. (C) Aurora A (wild-type or proteins with S349A, S349D, S290A/S291A, or S290/291D mutations), some of which were pre-incubated with recombinant GSK-3, were used to phosphorylate the CPEB-derived peptide linked to ovalbumin. Top panel: radiolabeled Ova-WT peptide; middle and bottom panels: Coomassie blue staining of gels showing equal loading of Ova-WT and Aurora A. Note that the Aurora A proteins containing aspartate (D) substitutions have slightly faster electrophoretic mobilities than wild-type or alanine (A)-containing proteins. (D) E. coli-expressed phosphatase-treated Aurora A wild-type and S290A/S291A mutant were incubated in extracts from immature extracts supplemented with $\gamma^{32} \mathrm{P}$-ATP. The resulting phosphorylated Aurora proteins were resolved by 2D phospho-peptide mapping as in Fig. 5. The arrow denotes the S349-containing phospho-peptide. (E) To determine the effects of Aurora A S290A/S291A and S349A on CPE-mediated mRNA polyadenylation, oocytes were co-injected with recombinant Aurora A proteins (wild-type or mutant) and in vitro synthesized radiolabeled CPE-containing RNA (cf. Fig. 1). The oocytes were incubated with progesterone $(0.01 \mu \mathrm{g} / \mathrm{mL}), \mathrm{harvested}$ 0,2 , or $4 \mathrm{~h}$ later, and processed for polyadenylation analysis (lower panel).

against human Aurora A phospho-T288 (Eyers et al. 2003; Tsai et al. 2003). To verify that this antibody could recognize the Xenopus form of phospho-T288 (which corresponds to phospho-T295), recombinant wild-type (active) or T294A/T295A mutant (kinase-dead) Aurora A proteins (both derived from Xenopus) were subjected to 
A

\begin{tabular}{l} 
GSK-3 western \\
\cline { 2 - 5 } \multicolumn{4}{c|}{} \\
\begin{tabular}{|l|c|c|c|}
\hline Protein A & + & - & - \\
\hline GSK-3 IP & - & + & - \\
\hline Extract & - & - & + \\
\hline
\end{tabular}
\end{tabular}

GSK-3 phosphorylation site

\begin{tabular}{c|cr}
1 & $P$ & 26 \\
GS WT YRRAAVPPSPSLSRHSS PHQSEDEEE \\
GS MT YRRAAVPPSPSLSRHSSPHQAEDEEE
\end{tabular}

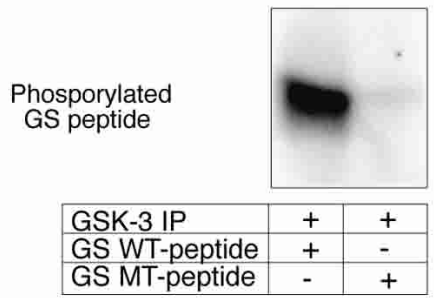

B
291295
Aurora peptide WT GWSVHAPSSRRTTLCGTLC
Aurora peptide MT GWSVHAPAARRTTLCGTLC
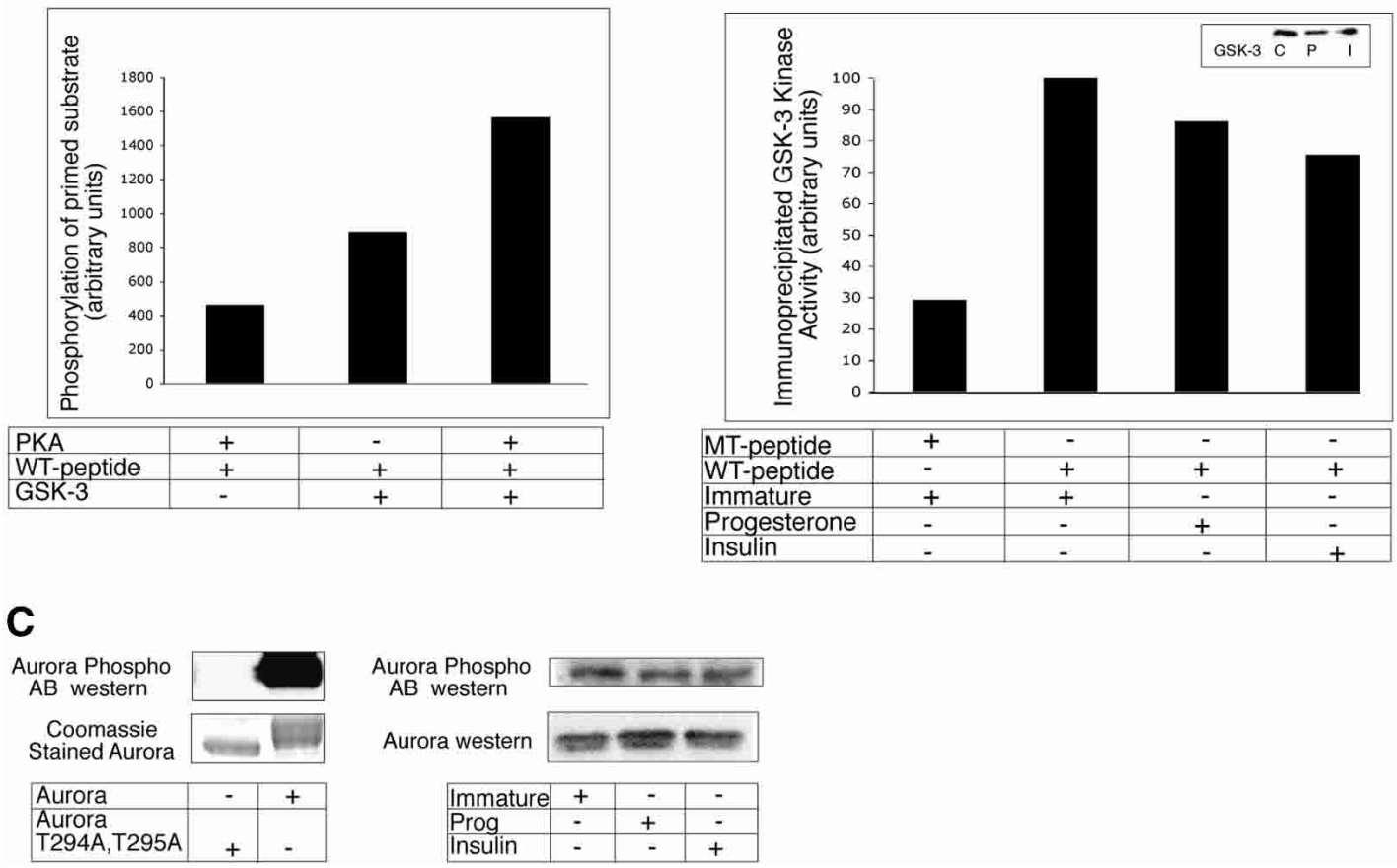

Figure 7. GSK-3 mediated Aurora A phosphorylation decreases during oocyte maturation. (A) A Western blot (top panel) verifies that GSK-3 can be immunoprecipitated from immature extracts (lane 2), but not when extracts were incubated with protein A beads alone (lane 1). Lane 3 shows GSK-3 in unfractionated extracts. The bottom panel shows that immunoprecipitated GSK-3 phosphorylates a wild-type (WT) GSK-3 substrate peptide containing a "priming" phosphate at S21 (derived from glycogen synthase), but not a peptide with an S21A mutation, which removes the priming phosphorylation. The site of GSK-3 phosphorylation on the peptide (at S17) is noted. (B) A peptide derived from Xenopus Aurora A was phosphorylated with PKA and then used as a substrate for GSK-3 that had been immunoprecipitated from extracts derived from immature oocytes. The relative amount of peptide phosphorylation was quantified by a phosphorimager (left). This same peptide, as well as one with S290A/S291A mutations, was used as a substrate for GSK-3 that had been immunoprecipitated from control, progesterone-treated, or insulin-treated oocytes (the boxed Western blot shows equal GSK-3 immunoprecipitation). As above, the extent of phosphorylation was quantified by a phosphorimager (right). (C) Recombinant Xenopus wild-type Aurora A, or an Aurora with T294/295A mutations were Western blotted and probed with anti-human Aurora A phospho-specific T295 antibody. The gel was also stained with Coomassie blue to show equal loading of the gel (left). Protein from immature, progesterone-treated, and insulin-treated oocytes was Western blotted and probed with both the Aurora A phospho-specific T295 antibody and conventional Aurora A antibody. 
Western blotting analysis. Only the wild-type protein was detected on the Western blot, which demonstrates that the anti-human antibody specifically recognizes frog Aurora A only when it is phosphorylated on T295. This antibody was then used to probe a Western blot of protein from immature and progesterone- and insulinmatured oocytes. Aurora A phospho-T295 was detected in all samples in equal amounts, which shows that not only is this "activating" phosphorylation present on inactive protein (in immature oocytes), but that this phosphorylation does not increase as the protein becomes active. Thus, other events, such as the inhibitory GSK-3 phosphorylation, must be alleviated as maturation proceeds.

\section{Discussion}

Our studies suggest several key signaling events in progesterone- and insulin-induced oocyte maturation (Fig. 8). Both signaling pathways activate CPEB-mediated mos mRNA polyadenylation and translation and all the previously established downstream events such as MPF activation and germinal vesicle breakdown (Mendez and Richter 2001). The events upstream of CPEB, however, show some pathway-specific characteristics. For example, oocytes do not respond to insulin treatment unless they are derived from frogs that had been "primed" with a subovulatory injection of a gonadotropic hormone. The gonadotropin induces the synthesis of IRS-1 in oocytes (Chuang et al. 1993a,b) which when phosphorylated by ligand binding to the insulin receptor tyrosine kinase activates PI3 kinase and the atypical PKC$\zeta$. The progesterone pathway does not require either of these kinases. Most importantly, however, both pathways inactivate GSK-3, a kinase that indirectly inhibits CPEB S174 phosphorylation and mos RNA polyadenylation. GSK-3 would thus appear to act constitutively in immature oocytes by phosphorylating Aurora A on residue(s) S290/291. This event induces Aurora A to autophosphorylate S349, which keeps this kinase inactive; hence, CPEB is neither phosphorylated nor active. The small but discernible inactivation of GSK-3 by progesterone or insulin presumably is accompanied by phosphatase activity that dephosphorylates both S290/291 and S349 on Aurora A, allowing this kinase to become active. Interestingly, the "activating" T295 phosphorylation appears to be present on inactive Aurora A in immature oocytes; the level of this phosphorylation event does not increase as maturation proceeds.

Aurora undergoes several phosphorylation events that are cell-cycle-controlled. Walter et al. (2000) first demonstrated that at least in vitro, Aurora B could be phosphorylated and activated by PKA. This PKA site is conserved in all Aurora proteins, including T295 in Xenopus Aurora A. Interestingly, those investigators used recombinant enzyme, which based on our observations and those of others (Littlepage et al. 2002: Eyers et al. 2003) was probably already phosphorylated and active. In another study, Frank-Valliant and colleagues (2000) noted that during oocyte maturation, Aurora A / referred to as

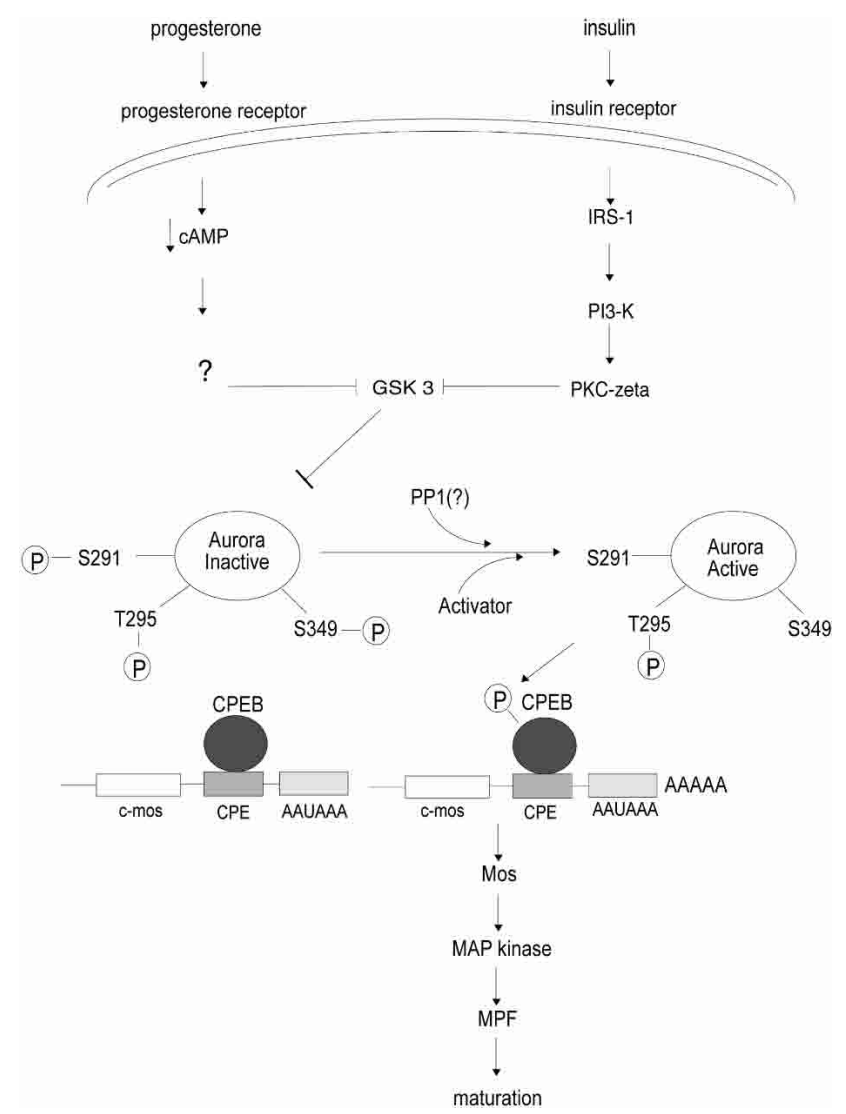

Figure 8. Proposed signaling pathways used by progesterone and insulin to stimulate oocyte maturation. Whereas insulin signals through insulin receptor substrate 1 (IRS-1), PI3 kinase, and $\mathrm{PKC}-\zeta$, progesterone uses none of these components. Both pathways, however, converge on and inactivate GSK-3. In the immature oocyte, GSK-3 phosphorylates Aurora A S290/S291, which in turn stimulates an Aurora A inhibitory autophosphorylation on S349. GSK-3 inactivation leads to the dephosphorylation of these residues, which is required for Aurora A activation. Other components, such as TPX2, may be involved in Aurora A activation at this time. It is noteworthy that T295 phosphorylation, which is important for kinase activity, is observed in both immature and mature oocytes. Active Aurora A then phosphorylates CPEB S174, which induces polyadenylation and translation of mos mRNA. Mos protein subsequently stimulates the Map kinase cascade, MPF activation, and oocyte maturation.

Eg2) underwent an SDS gel mobility shift typical during germinal vesicle breakdown, which occurs with several proteins that are phosphorylated by MPF that becomes active at this time. However, Aurora A does not appear to be a substrate of MPF, as the addition of roscovitin, an MPF inhibitor, to egg extracts had no effect on Aurora A phosphorylation (Littlepage et al. 2002). Moreover, we could not phosphorylate Aurora A in vitro with purified MPF (data not shown).

An increase in Aurora A activity subsequent to MPF activation and germinal vesicle breakdown that was observed by Frank-Valliant et al. (2000) could be due, at least in part, to increased translation of Aurora A 
mRNA. In Xenopus, Aurora A (Eg2) was one of several mRNAs identified initially as undergoing polyadenylation during the transition from an (immature) oocyte to an egg (Paris et al. 1988). Many CPE-containing mRNAs, with mos being a notable exclusion, undergo polyadenylation-induced translation after MPF activation, when it is necessary to partially destroy CPEB (de Moor and Richter 1997; Mendez et al. 2002). The 3' UTR of Aurora A mRNA contains putative CPEs, and these might drive polyadenylation and translation subsequent to MPF activation.

Using extracts derived from Xenopus eggs arrested at metaphase II, Littlepage et al. (2002) performed mass spectrometry to identify three prominent sites of phosphorylation: S53, T295, and S349. They ascribed a stimulatory activity to phospho-T295 and an inhibitory activity to phospho-S349. Phospho-T295 has subsequently been shown to be a site of autophosphorylation that is stimulated by TPX2 (target protein for Xenopus kinesinlike protein 2), a spindle protein that is regulated by the Ran GTPase (Eyers et al. 2003; Tsai et al. 2003). In one study, TPX2 stimulation of Aurora A phosphorylation and activation also required microtubules (Tsai et al. 2003); but in another study (Eyers et al. 2003), this was not the case.

Although TPX2 and PKA both modulate Aurora A activity during mitosis, the extent to which they do so during oocyte maturation is unclear. For example, T295, whose phosphorylation is necessary for Aurora A activation, lies within a PKA site that is phosphorylated by this kinase in vitro (Walter et al. 2000). However, PKA activity, which is thought to be high in oocytes, must decrease, at least transiently, for maturation to occur (e.g., Sadler and Maller 1981). Such a decrease would be inconsistent with Aurora A activation. Indeed, our results show that T295 is already phosphorylated in immature oocytes (Fig 7B), and that there is no detectable increase during maturation. This observation points to other sites on Aurora A (i.e., those phosphorylated by GSK-3) that are important for keeping this kinase inactive until maturation is initiated. Whether PKA is responsible for the phosphorylation of T295 in immature oocytes is unclear. In fact, recent evidence by Schmidt and Nebreda (2002) suggests that PKA effects on oocyte maturation do not even require catalytic activity of the enzyme; this would also be inconsistent with Aurora A activation by PKA. It is certainly possible that other kinases, which might be active early during maturation, recognize and phosphorylate T295.

Andersen et al. $(1998,2003)$ demonstrated that the protein kinase $\mathrm{PKB} / \mathrm{AKT}$ can stimulate oocyte maturation. $\mathrm{PKB} / \mathrm{AKT}$, like PKC- $\zeta$, is a component of the insulin signaling pathway that inhibits GSK-3 activity (Frame and Cohen 2001; Oriente et al. 2001). Although we have no evidence to suggest that $\mathrm{PKB} / \mathrm{AKT}$ can promote CPEmediated translation, as is the case with PKC- $\zeta$ (Fig. 3), it may be that PKB/AKT and PKC- $\zeta$ work together to fully inhibit GSK-3 activity. For example, in L6hIR muscle cells, Oriente et al. (2001) found that complete GSK-3 inhibition by insulin stimulation required the activity of both PKC- $\zeta$ and PKB/AKT. In vitro, the GSK-3 activity with $\mathrm{PKB} / \mathrm{AKT}$ phosphorylation was found to be only $35 \%-40 \%$ inhibited; however, GSK-3 pretreated with PKC- $\zeta$ followed by $\mathrm{PKB} / \mathrm{AKT}$ phosphorylation reduced GSK-3 activity by more than $70 \%$ (Oriente et al. 2001). Thus, insulin stimulation of oocyte maturation might require the combined activity of both $\mathrm{PKC}-\zeta$ and $\mathrm{PKB} /$ AKT to fully inhibit GSK-3 and thereby lead to Aurora A activation.

The Xenopus oocyte model for insulin-induced maturation could have important implications for insulin signaling in other contexts. For example, CPEB-dependent polyadenylation might occur in some mammalian somatic cells stimulated with insulin. In addition, signaling events initiated by ligands other than insulin could require regulation of Aurora by GSK-3. Consider also that the control of CPEB-mediated polyadenylation at synapses of hippocampal neurons appears to be regulated by Aurora-catalyzed phosphorylation (Huang et al. 2002), and we would posit that Aurora activity, which is controlled by $\mathrm{N}$-methyl-D-aspartate receptor signaling, might be regulated by GSK-3. Although GSK-3 is neuronal (Graef et al. 1999), it is unclear whether it is postsynaptic; this possible localization, and its role in CPEB activity, if any, is under investigation.

\section{Materials and methods}

\section{Oocyte preparation and injections}

Xenopus laevis females were injected with pregnant mare serum gonadotropin (50 IU); 4 to $7 \mathrm{~d}$ later, ovarian lobes were removed and treated with collagenase and dispase (de Moor and Richter 1997), and stage VI oocytes were selected and cultured in Barth's medium for all procedures. Oocytes were injected with $30 \mathrm{~nL}$ of the indicated in vitro transcribed radiolabeled or radioinert mRNA suspended in water at a concentration of 0.1 to $0.5 \mu \mathrm{M}$. Mos antisense oligonucleotide was injected as described (de Moor and Richter 1997). PKC- $\zeta$ and PKC- $\alpha$ inhibitor peptides were obtained from Bioscience International and suspended in water at a concentration of $1 \mathrm{mg} / \mathrm{mL}$. PKC peptides were injected $2 \mathrm{~h}$ before induction of maturation by progesterone or insulin. To induce maturation, oocytes were incubated in media containing insulin $(5-50 \mu \mathrm{M})$ or progesterone $(1 \mu \mathrm{M})$ for 3-6 $\mathrm{h}$ (progesterone) or 8-16 h (insulin). After incubation, the oocytes were collected and frozen on solid $\mathrm{CO}_{2}$ and stored at $-80^{\circ} \mathrm{C}$. In vitro synthesis of mRNAs encoding myc-tagged CPEB and GSK-3 proteins has been described (Pierce and Kimelman 1995; Mendez et al. 2000a). Oocytes were treated with rapamycin $(2 \mu \mathrm{g} / \mathrm{mL})$ or wortmannin $(0.5 \mu \mathrm{M})$ as described (Liu et al. 1995; Schwab et al. 1999).

\section{Kinase assays}

For kinase assays, 10 oocytes were homogenized in $200 \mu \mathrm{L}$ of $\mathrm{H} 1$ kinase buffer $(80 \mathrm{mM}$ sodium $\beta$-glycerophosphate, $20 \mathrm{mM}$ EGTA, $15 \mathrm{mM} \mathrm{MgCl} 2,50 \mathrm{mM} \mathrm{NaVaO}$ ) containing protease inhibitors (leupeptin, pepstatin, and chymostatin, each at 10 $\mathrm{\mu g} / \mathrm{mL}$ ) and centrifuged for $5 \mathrm{~min}$ at $4^{\circ} \mathrm{C}$ at $15,000 \mathrm{~g}$. E. coliexpressed his-tagged CPEB protein was obtained as described (Stebbins-Boaz et al. 1996). The peptides VRGSRLDTRPILDSRSS (wild-type) and peptide VRGSRLDARPILDARSS (mutant) corresponding to residues 163 to 181 on murine CPEB, which contained a C-terminal cysteine, were coupled to maleimideactivated ovalbumin (Pierce). Kinase assays for CPEB phos- 
phorylation were performed in a total volume of $40 \mu \mathrm{L}$ containing $20 \mu \mathrm{L}$ of kinase buffer $[10 \mathrm{mM} \mathrm{MgCl}, 1 \mathrm{mM}$ dithiothreitol, $20 \mathrm{mM}$ HEPES pH 7.7, $50 \mathrm{mM} \mathrm{KCl}$, and $30 \mu \mathrm{M}\left(\gamma_{-}{ }^{32} \mathrm{P}\right)$ ATP $(0.16$ $\left.\left.\mathrm{mCi} \mathrm{mL}^{-1}\right)\right], 10 \mu \mathrm{L}$ of CPEB substrate $(0.5 \mu \mathrm{g})$, and $10 \mu \mathrm{L}$ of extracts prepared from mock, progesterone-, or insulin-stimulated oocyte extracts. Kinase assays for MPF activity was conducted as in de Moor and Richter (1997). Reaction mixtures were incubated for $15 \mathrm{~min}$ at $30^{\circ} \mathrm{C}$ followed by $2 \mathrm{D}$ phosphopeptide mapping (Boyle at al. 1991). Xenopus Aurora A (Andresson and Ruderman 1998) was cloned into pet30a vector, expressed in E. coli, and purified on Ni-agarose beads (QIAGEN). Aurora A truncations were generated by PCR using oligodeoxynucleotides complementary to sequences within the C-terminus. Aurora K169R, S349A, S290A/S291A, T294A/T295A, S290D/S291D, and S349D mutations were made using a Stratagene Site-Directed Mutagenesis Kit. Recombinant Aurora was dephosphorylated by $\lambda$-phosphatase (New England Biolabs). GSK-3 kinase assays were performed as described by the manufacturer (Upstate). Inactivation of Aurora kinase proteins by GSK-3 was conducted by first incubating Aurora A with GSK-3 in GSK-3 kinase buffer (Upstate) for $30 \mathrm{~min}$ at $30^{\circ} \mathrm{C}$. Aurora was then extracted using $\mathrm{Ni}$-agarose beads for $2 \mathrm{~h}$ at $4^{\circ} \mathrm{C}$. These beads were then washed and incubated with Ova-WT peptide in the kinase buffer described for CPEB phosphorylation (above) for $30 \mathrm{~min}$ at $30^{\circ} \mathrm{C}$, followed by SDS-PAGE and autoradiography. GSK-3 substrate peptides derived from glycogen synthase (GS WT, containing a priming phospho-serine at residue 21; GS MT, containing S21A, which cannot be primed) were obtained from Upstate and used at a concentration of $0.5 \mathrm{mg} / \mathrm{mL}$. Aurora A peptides (WT GWSVHAPSSRRTTLCGTLC and MT GWSVHAPAARRTTLCGTLC) corresponding to residues 283-300 of Aurora A were used at a concentration of $1 \mathrm{mg} / \mathrm{mL}$. The peptides were incubated with immunoprecipitated GSK-3 in GSK-3 kinase buffer as described above, followed by SDS-PAGE and autoradiography.

Immunodepletion of Aurora $A$ and immunoprecipitation of GSK-3

Rabbit antiserum was generated against bacterially expressed his-tagged Xenopus Aurora A (Eg2, Andresson and Ruderman 1998). Immunodepletion of Aurora from oocyte extracts was conducted as described (Hake and Richter 1994; Mendez et al. 2000a) using specific antibody coupled to protein A Sepharose. The depleted extract was then used in a kinase assay with substrate CPEB peptide coupled to ovalbumin (see above and Mendez et al. 2000a). Immunoprecipitation of GSK-3 from immature, progesterone-, or insulin-matured oocytes was performed as described (Fisher et al. 1999).

\section{Polyadenylation and Western procedures}

To assay polyadenylation of injected radiolabeled CPE containing or lacking RNA (de Moor et al. 1997), total RNA was isolated from oocytes that had been injected with radiolabeled RNA by the p-aminosalicylic acid-sodium dodecyl sulfate (SDS) method (de Moor and Richter 1997). The RNA was analyzed by electrophoresis on a $6 \%$ polyacrylamide gel containing $50 \%$ urea and $1 \mathrm{X}$ Tris-borate-EDTA buffer and phosphorimaging. Western blotting was performed as discussed by Mendez et al. (2000a). Anti-phospho-T295 Aurora A antibody was purchased from Cell Signaling Technology.

\section{Acknowledgments}

We thank David Kimelman, David Fisher, and Chris Proud for reagents. This work was supported by a grant from the NIH
(GM46779). Additional research support from the Diabetes Endocrinology Research Center (grant DK32520) is gratefully acknowledged.

The publication costs of this article were defrayed in part by payment of page charges. This article must therefore be hereby marked "advertisement" in accordance with 18 USC section 1734 solely to indicate this fact.

\section{References}

Andersen, C., Roth, R.A., and Conti, M. 1998. Protein kinase B/Akt Induces resumption of meiosis in Xenopus oocytes. J. Biol. Chem. 273: 18705-18708.

Andersen, C., Sakaue, H., Nedachi, T., Kovacina, K.S., Clayberger, C., Conti, M., and Roth, R.A. 2003. Protein kinase $\mathrm{B} / \mathrm{Akt}$ is essential for the insulin- but not progesteronestimulated resumption of meiosis in Xenopus oocytes. Biochem. J. 369: 227-238.

Andresson, T. and Ruderman, J.V. 1998. The kinase Eg2 is a component of the Xenopus oocyte progesterone-activated signaling pathway. EMBO J. 17: 5627-5637.

Berra, E., Diaz-Meco, M.T., Dominguez, I., Municio, M.M., Sanz, L., Lozano, J., Chapkin, R.S., and Moscat, J. 1993. Protein kinase $\mathrm{C}$ zeta isoform is critical for mitogenic signal transduction. Cell 74: 555-563.

Bijur, G.N., De Sarno, P., and Jope, R.S. 2000. Glycogen synthase kinase-3B facilitates staurosporine and heat shock induced apoptosis. J. Biol. Chem. 275: 7583-7590.

Boyle, W.J., van der Geer, P., and Hunter, T. 1991. Phosphopeptide mapping and phosphoamino acid analysis by two-dimensional separation on thin layer cellulose plates. Methods Enzymol. 201: 110-149.

Cantley, L.C. 2002. The phosphoinositide 3-kinase pathway. Science 296: 1655-1657.

Cao, Q. and Richter, J.D. 2002. Dissolution of the maskin-eIF4E complex by cytoplasmic polyadenylation and poly(A)-binding protein controls cyclin B1 mRNA translation and oocyte maturation. EMBO J. 21: 3852-3862.

Chuang, L.M., Myers, M.G., Seidner, G.A., Birnbaum, M.J., White, M.F., and Kahn, R.C. 1993a. Insulin receptor substrate 1 mediates insulin and insulin-like growth factor 1-stimulated maturation of Xenopus oocytes. Proc. Natl. Acad. Sci. 90: 5172-5175.

Chuang, L.M., Myers, M.G., Backer, J.M., Shoelson, S.E., White, M.F., Birnbaum, M.J., and Kahn, R.C. 1993b. Insulin-stimulated oocyte maturation requires insulin receptor substrate 1 and interaction with the SH2 domains of phosphatidylinositol 3-kinase. Mol. Cell. Biol. 13: 6653-6660.

de Moor, C.H. and Richter, J.D. 1997. The mos pathway regulates cytoplasmic polyadenylation in Xenopus oocytes. Mol. Cell. Biol. 17: 6419-6426.

Dominguez, I., Diaz-Meco, M.T., Municio, M.M., Berra, E., Garcia de Herreros, A., Cornet, M.E., Sanz, L., and Moscat, J. 1992. Evidence for a role of protein kinase C zeta subspecies in maturation of Xenopus laevis oocytes. Mol. Cell. Biol. 12: $3776-3783$.

Eyers, P.A., Erikson E., Chen, L.G., and Maller, J.L. 2003. A novel mechanism for activation of the protein kinase Aurora A. Curr. Biol. 13: 691-697.

Ferrell, J.E. 1999. Xenopus oocyte maturation: New lessons from a good egg. BioEssays 21: 833-842.

Fisher, D.J., Morin, N., and Doree, M. 1999. A novel role for glycogen synthase kinase-3 in Xenopus development: Maintenance of oocyte cell cycle arrest by a $\beta$-catenin-independent mechanism. Development 126: $567-576$ 
Frame, S. and Cohen, P. 2001. GSK3 takes center stage more than 20 years after its discovery. Biochem. J. 359: 1-16.

Frank-Vaillant, M., Haccard, O., Thibier, C., Ozon, R., ArlotBonnemains, Y., Prigent, C., and Jessus, C. 2000. Progesterone regulates the accumulation and activation of Eg2 kinase in Xenopus oocytes. J. Cell Sci. 113: 1127-1138.

Gingras, AC., Raught, B., and Sonenberg, N. 2001. Regulation of translation initiation by FRAP/mTOR. Genes \& Dev. 15: 807-826.

Graef, I.A., Mermelstein, P.G., Stankunas, K., Neilson, J.R., Deisseroth, K., Tsien, R.W., and Crabtree, G.R. 1999. L-type calcium channels and GSK-3 regulate the activity of NFATc4 in hippocampal neurons. Nature 401: 703-708.

Hake, L.E. and Richter, J.D. 1994. CPEB is a specific factor that mediates cytoplasmic polyadenylation during Xenopus oocyte maturation. Cell 79: 617-628.

Huang Y.S., Jung, M.Y., Sarkissian, M., and Richter, J. 2002. $\mathrm{N}$-methyl-D-aspartate receptor signaling results in Aurora kinase-catalyzed CPEB phosphorylation and $\alpha \mathrm{CaMKII}$ mRNA polyadenylation at synapses. EMBO J. 21: 2139-2148.

Kozma, S.C. and Thomas, G. 2002. Regulation of cell size in growth, development and human disease: PI3K, PKB and S6K. BioEssays 24: 65-71.

Littlepage, L.E., Wu, H., Andersson, T., Deanehan, J.K., Amundadottir, L.T., and Ruderman, J.V. 2002. Identification of phosphorylated residues that affect the activity of the mitotic kinase Aurora-A. Proc. Nat1. Acad. Sci. 99: 15440-15445.

Liu, J. and Schwartz, J.H. 2003. The cytoplasmic polyadenylation element binding protein and polyadenylation of messenger RNA in Aplysia neurons. Brain Res. 959: 68-76.

Liu, X.J., Sorisky, A., Zhu, L., and Pawson, T. 1995. Molecular cloning of an amphibian insulin receptor substrate 1-Like cDNA and involvement of phosphatidylinositol 3-kinase in insulin-induced Xenopus oocyte maturation. Mol. Cell. Biol. 15: 3563-3570.

Ma, C., Cummings, C., and Liu, X.J. 2003. Biphasic activation of Aurora-A kinase during the meiosis I- meiosis II transition in Xenopus oocytes. Mol. Cell. Biol. 23: 1703-1716.

Mendez, R. and Richter, J.D. 2001. Translational control by CPEB: A means to the end. Nat. Rev. Mol. Cell. Biol. 2: 521-529.

Mendez, R., Hake, L.E., Andresson, T., Littlepage, L.E., Ruderman, J.V., and Richter, J.D. 2000a. Phosphorylation of CPE binding factor by Eg2 regulates translation of c-mos mRNA. Nature 404: 302-307.

Mendez, R., Murthy, K.G.K., Ryan, K., Manley, J.L., and Richter, J.D. 2000b. Phosphorylation of CPEB by Eg2 mediates the recruitment of CPSF into an active cytoplasmic polyadenylation complex. Mol. Cell. Biol. 6: 1253-1259.

Mendez, R., Welsh, G., Kleijn, M., Myers, M.G., White, M.F., Proud, C.G., and Rhoads, R.E. 2001. Regulation of protein synthesis by insulin through IRS-1. Prog. Molec. Subcell. Biol. 26: 49-93.

Mendez, R., Barnard, D., and Richter, J.D. 2002. Differential mRNA translation and meiotic progression require Cdc2mediated CPEB destruction. EMBO J. 21: 1833-1844.

Oriente, F., Formisano, P., Miele, C., Fiory F., Maitan, M.A., Vigliotta, G., Trencia, A., Santopietro, S., Caruso, M., Obberghen, E.V., et al. 2001. Insulin receptor substrate-2 phosphorylation is necessary for protein kinase $\mathrm{C}$ zeta activation by insulin in L6hIR cells. J. Biol. Chem. 276: 3710937119.

Paris, J., Osborne, H.B., Couturier, A., Le Guellac, R., and Philippe, M. 1988. Changes in the polyadenylation of specific stable RNA during the early development of Xenopus laevis. Gene 72: 169-176.

Paris, J., Swenson, K., Piwnica-Worms, H., and Richter, J.D.
1991. Maturation-specific polyadenylation: In vitro activation by $\mathrm{p} 34^{\mathrm{cdc} 2}$ and phosphorylation of a $58-\mathrm{kD}$ CPE-binding protein. Genes \& Dev. 5: 1697-1708.

Pierce, S.B. and Kimelman, D. 1995. Regulation of Spemann organizer formation by the intracellular kinase Xgsk-3. Development 121: 755-765.

Richter, J.D. 2000. The influence of polyadenylation-induced translation on metazoan development and neuronal synaptic function. In Translational control of gene expression (eds. M.B. Matthews et al.), pp. 785-805. Cold Spring Harbor Laboratory Press, Cold Spring Harbor, NY.

Sadler, S.E. and Maller, J.L. 1981. Progesterone inhibits adenylate cyclase in Xenopus oocytes. Action on the guanine nucleotide regulatory protein. J. Biol. Chem. 256: 6368-6373.

-1989. A similar pool of cyclic AMP phosphodiesterase in Xenopus oocytes is stimulated by insulin, insulin-like growth factor 1 , and $\left[\mathrm{Val}^{12}\right.$, Thr $\left.{ }^{59}\right]$ Ha-ras protein. J. Biol. Chem. 264: 856-861.

Sagata, N., Oskarsson, M., Copeland, T., Brumbaugh, J., and vande Woude, G.F. 1988. Function of c-mos proto-oncogene product in meiotic maturation in Xenopus oocytes. Nature 335: 519-525.

Schmelzle, T. and Hall, M.N. 2000. TOR, a central controller of cell growth. Cell 103: 253-262.

Schmitt, A. and Nebreda, A.R. 2002. Inhibition of Xenopus oocyte meiotic maturation by catalytically inactive protein kinase A. Proc. Natl. Acad. Sci. 99: 4361-4366.

Schwab, M.S., Kim, S.H., Terada, N., Edfjall, C., Kozma, S.C., Thomas, G., and Maller, J.L. 1999. p70 ${ }^{\text {S6K }}$ controls selective mRNA translation during oocyte maturation and early embryogenesis in Xenopus laevis. Mol. Cell. Biol. 19: 24852494.

Stebbins-Boaz, B., Hake, L.E., and Richter, J.D. 1996. CPEB controls the cytoplasmic polyadenylation of cyclin, CDK2 and c-mos mRNA and is necessary for oocyte maturation in Xenopus. EMBO J. 15: 2582-2592.

Stebbins-Boaz, B., Cao, Q., de Moor, C.H., Mendez, R., and Richter, J.D. 1999. Maskin is a CPEB-associated factor that transiently interacts with eIF-4E. Mol. Cell 4: 10171027.

Tsai, M.Y., Wiese, C., Cao, K., Martin, O., Donovan, P., Ruderman, J., Prigent, C., and Zheng, Y. 2003. A Ran signaling pathway mediated by the mitotic kinase Aurora A in spindle assembly. Nat. Cell Biol. 5: 242-248.

Walter, A.O., Seghezzi, W., Korver W., Sheung, J., and Lees, E. 2000. The mitotic serine/threonine kinase Aurora2/AIK is regulated by phosphorylation and degradation. Oncogene 19: 4906-4916.

Wells, D.G., Dong, X., Quinlan, E.M., Huang, Y.S., Bear, M.F., Richter, J.D., and Fallon, J.R. 2001. A role for the cytoplasmic polyadenylation element in NMDA receptorregulated mRNA translation in neurons. I. Neurosci. 21: 9541-9548.

Wu, L., Wells, D., Tay, J., Mendis, D., Abbott, M., Barnitt, A., Quinlan, E., Heynen, A., Fallon, J., and Richter, J.D. 1998. CPEB-mediated cytoplasmic polyadenylation and the regulation of experience-dependent translation of $\alpha$-CaMKII mRNA at synapses. Neuron 21: 1129-1139.

Wymann, M.P., Bulgarelli-Leva, G., Zvelebil, M.J., Pirola, L., Vanhaesebroeck, B., Waterfield, M.D., and Panayotou, G. 1996. Wortmannin inactivates phosphoinositide 3-kinase by covalent modification of Lys-802, a residue involved in the phosphate transfer reaction. Mol. Cell. Biol. 16: 17221733. 


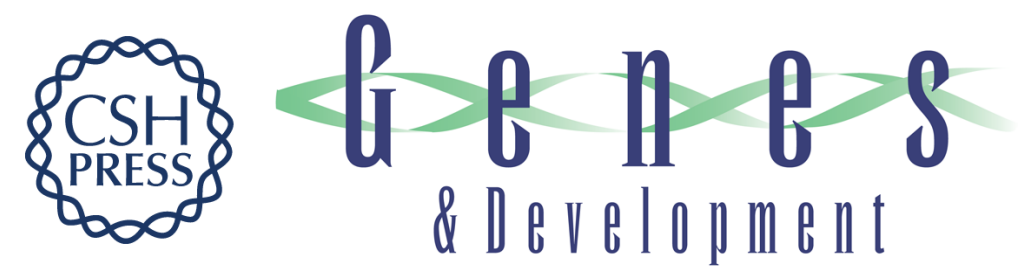

\section{Progesterone and insulin stimulation of CPEB-dependent polyadenylation is regulated by Aurora A and glycogen synthase kinase-3}

Madathia Sarkissian, Raul Mendez and Joel D. Richter

Genes Dev. 2004, 18:

Access the most recent version at doi:10.1101/gad.1136004

References This article cites 48 articles, 26 of which can be accessed free at:

http://genesdev.cshlp.org/content/18/1/48.full.html\#ref-list-1

License

Email Alerting Receive free email alerts when new articles cite this article - sign up in the box at the top Service right corner of the article or click here.

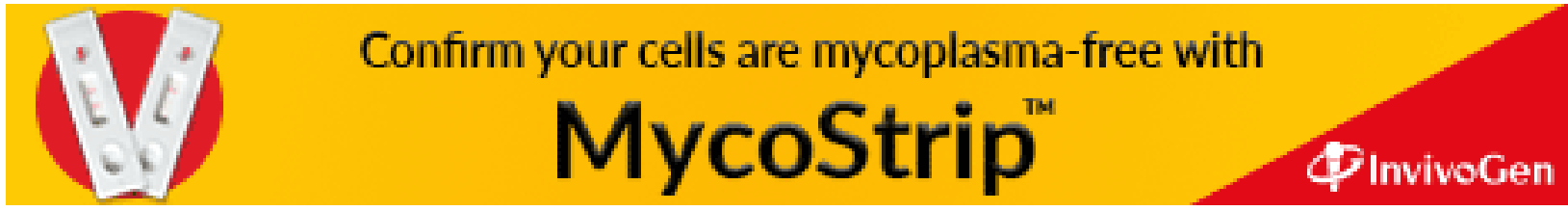

